$$
\begin{array}{r}
\text { Pontifícia Universidade Católica } \\
\text { do Rio de Janeiro }
\end{array}
$$

Mariana Patrício Fernandes

\title{
VIDA SURGIDA RÁPIDA, LOGO APAGADA - EXTINTA A criação de estratégias de fuga do hospício na escrita de Maura Lopes Cançado
}

\section{Dissertação de Mestrado}

Dissertação de Mestrado apresentada como requisito parcial para obtenção do grau de Mestre em Letras do Departamento de Letras da PUC-Rio como parte dos requisitos parciais para obtenção do título de Mestre em Letras.

Orientadora: Profa. Ana Paula Veiga Kiffer 


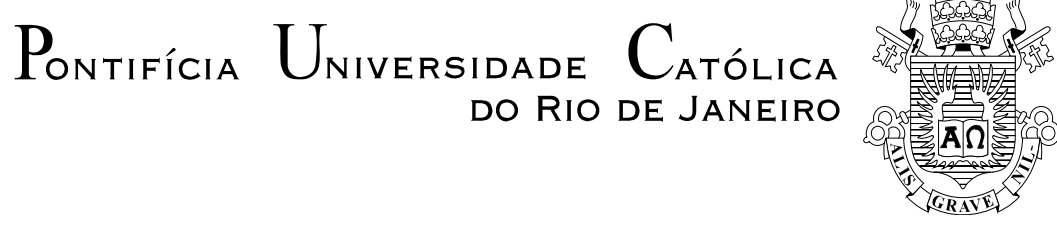

Mariana Patrício Fernandes

\begin{abstract}
VIDA SURGIDA RÁPIDA, LOGO APAGADA - EXTINTA A criação de estratégias de fuga do hospício na escrita de Maura Lopes Cançado
\end{abstract}

\title{
Dissertação de Mestrado
}

\begin{abstract}
Dissertação apresentada como requisito parcial para obtenção do grau de Mestre pelo programa de PósGraduação em Letras do Departamento de Letras do Centro de Teologia e Ciências Humanas da PUC-Rio. Aprovada pela Comissão Examinadora abaixo assinada.
\end{abstract}

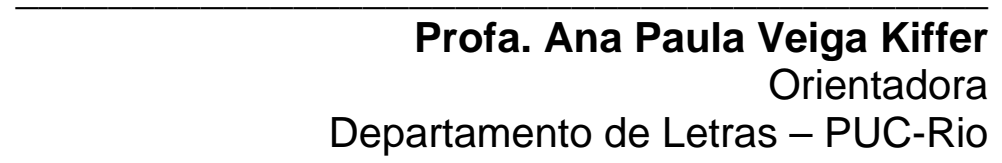

Profa. Marília Rothier Cardoso

Departamento de Letras - PUC-Rio

Prof. Italo Moriconi Junior

UERJ

Prof. Prof. Paulo Fernando Carneiro de Andrade

Coordenador Setorial do Centro de Teologia

e Ciências Humanas - PUC-Rio

Rio de Janeiro, de de 
Todos os direitos reservados. É proibida a reprodução total ou parcial do trabalho sem autorização da universidade, da autora e da orientadora.

\section{Mariana Patrício Fernandes}

Graduou-se em História pela Pontifícia Universidade Católica do Rio de Janeiro, e cursou o mestrado em Literatura Brasileira no Departamento de Letras da mesma universidade

Ficha Catalográfica

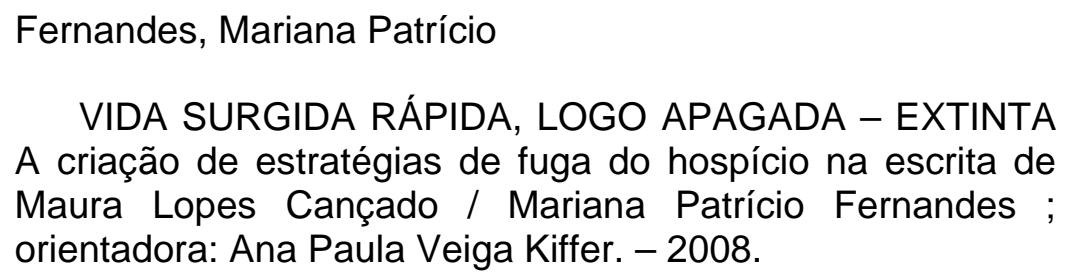

VIDA SURGIDA RÁPIDA, LOGO APAGADA - EXTINTA A criação de estratégias de fuga do hospício na escrita de Maura Lopes Cançado / Mariana Patrício Fernandes ; orientadora: Ana Paula Veiga Kiffer. - 2008.

125 f. ; $30 \mathrm{~cm}$

Dissertação (Mestrado em Letras) - Pontifícia Universidade Católica do Rio de Janeiro, Rio de Janeiro, 2008.

Inclui bibliografia

1. Letras - Teses. 2. Escritas de si. 3. Loucura. 4. Clausura. 5. Modos de fuga. 6. Diários. 7. Hospício. I. Kiffer, Ana Paula Veiga. II. Pontifícia Universidade Católica do Rio de Janeiro. Departamento de Letras. III. Título. 


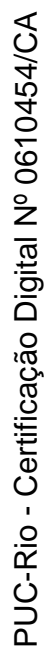

Para Pedro, meu amor, pelo encontro.

Aos meus pais, Luís e Inês, pelo carinho e pela formação. 


\section{Agradecimentos}

Por mais que já seja um lugar-comum dizer que o trabalho acadêmico é muito solitário, a impressão que tenho, depois de concluir esta dissertação, é que, ainda que a solidão tenha existido, foram poucos os momentos em que estive realmente sozinha. Gostaria de agradecer imensamente a todos que me acompanharam neste processo em especial:

À minha orientadora, Ana Paula Kiffer, pela confiança, pelo apoio, pelas leituras cuidadosas e, sobretudo, por sempre lançar questões instigantes e desafiadoras.

À Maura Lopes Cançado, pela experiência.

À Marília pelo Sofredor do Ver, e pelas discussões nas aulas que muito me acrescentaram.

Ao José Carlos Sebe Bom Meihy por ter me dado de presente Hospício é Deus e por todas as viagens históricas, turísticas e literárias que me proporcionou.

Ao Carlos Heitor Cony pela generosa entrevista, e à Ana Lee que nos apresentou.

Ao Professor Alberto Giordano, pela orientação em Rosário.

Aos professores Luiz Costa Lima, Karl Erik, Heidrun e Júlio pelas aulas estimulantes.

Aos meus companheiros de mestrado: Rodrigo, Ana Lee, Laura, Mariana, Daniel, Denise, e muitos outros. Aos meus companheiros de vida e profissão: Miguel, Lipe e Bárbara.

Aos de sempre e para sempre: Liza, Tainá, Chico, Branno, Clarinha Duarte, Clarinha Araujo, Piero, Ana Maria, Mariana Trotta, Mariana Kaufman, Pedrinho Gomes, Tininha, Saffira, Léo, Tati, Peninha, Carol Benjamin, Juliana, Alda, Rafa, Serginho, Ju, Yan Cândido, Marlon e Ana Júlia.

À Chiquinha pela ajuda em todos os momentos.

Ao meu irmão mais querido, Pedro, pela cumplicidade.

À Inês, minha mãe, pelo apoio incondicional, pelo amor à literatura, por nunca fazer do cotidiano uma realidade entediante.

Ao Luís, meu pai, pela firmeza, por nunca desesperar, pela descontração e pela tranqüilidade.

Ao Luiz, por estar sempre com um pé neste mundo e o outro em um muito maior: das estrelas, nebulosas, buracos negros e fractais. 
Á Clarinha pelo caminho percorrido nestas metamorfoses da vida.

Aos meus avós queridos, Rui, Mário, Puri e especialmente à minha avó Ignez, pela sabedoria.

Ao Carlos Augusto pelo apoio em todos os momentos.

À Cacá, Chiquinho, Aracy, Geraldo, Vicente, Ricardo, Gisele, Luizinha, pelo bom encontro.

Ao meu grande amor, Pedro. Fonte infinita de alegria. Esta dissertação jamais teria sido possível sem ele.

À CAPES, pelo apoio. 


\section{Resumo}

Fernandes, Mariana Patrício; Kiffer, Ana Paula Veiga (Orientadora). VIDA SURGIDA RÁPIDA, LOGO APAGADA - EXTINTA A criação de estratégias de fuga do hospício na escrita de Maura Lopes Cançado. Rio de Janeiro, 2008. 125p. Dissertação de Mestrado - Departamento de Letras, Pontifícia Universidade Católica do Rio de Janeiro.

O objetivo da dissertação é, a partir da obra de Maura Lopes Cançado, entender de que forma a escrita pode engendrar modos de fuga em uma situação aparentemente sem saída - como por exemplo, a internação em um hospital psiquiátrico, onde a escritora passou boa parte de sua vida. "Hospício- deus” é como Maura denomina esta sensação de clausura, que não se resume ao fato de estar internada, mas à outras experiências subjetivas, mais sutis e, por isso mesmo, mais difíceis de escapar. No entanto, é necessário fugir, pois é o próprio “desespero de fuga” e o “desejo de evasão”, que compõem a força motriz da sua escrita. Fez-se necessário neste trabalho, portanto, mapear a geografia do "hospício- deus”, em suas diferentes imagens, para elaborar através do diálogo entre o diário, a obra ficcional, e a leitura crítica, a melhor maneira de escapar a ele.

\section{Palavras-chave}

Escritas de si, loucura, clausura, modos de fuga, diários, hospício. 


\section{Abstract}

Fernandes, Mariana Patrício; Kiffer, Ana Paula Veiga (Advisor). LIFE EMERGED QUICKLY, ONCE CLEARED - EXTINCT The creation of strategies of escape in the writing of Maura Lopes Cançado. Rio de Janeiro, 2008. 125p. MSc Dissertation - Departamento de Letras, Pontifícia Universidade Católica do Rio de Janeiro.

The purpose of this work is, trough de writings of Maura Lopes Cançado, understand how literature is able to create ways of escape in situations where there are not, at least apparently, any exits, such as the confinement in a psychiatric hospital, where the writer spent most of her life. "Asylum-god" is how Maura called this sensation of enclosure, related also to other subjective experiences, more subtle and therefore more difficult to escape. However, it is necessary to flee, as it is the very "despair of escape" and the "desire of evasion", the driving force of her writing. It was necessary in this work, therefore, to map the geography of this "asylum-god " to develop through the dialogue between the diary, the fictional work, and the literary criticism, the best way to evade.

\section{Keywords}

Autobiographys, insanity, confinement, ways of escape, diary, insane asylum. 


\section{Sumário}

Introdução $\quad 10$

Percurso do Leitor, n.1 18

Capítulo I - Pacto de Evasão $\quad 23$

Caminhos 23

Visibilidades $\quad 25$

Permanecer sentado 31

Uma necessidade ideológica $\quad 33$

Fora do estojo 38

Paradoxos. 43

O diário como espaço da experiência 45

Escapando para dentro 50

Percurso do Leitor, n.2

Capitulo II - Claustrofobia

Trajetória em espiral $\quad 56$

A vanguarda da civilização 63

Cemitério dos Vivos 69

O assassinato do Espelho $\quad 73$

Hospício-Deus 75

Percurso do Leitor, n.3

Capítulo III - Em fuga $\quad \mathbf{8 6}$

Segredos do Pátio $\quad 86$

Loucura Santa $\quad 87$

Guerra 91

Desmoronamento 97

Feridas $\quad 100$

Vida surgida rápida 104

Barreiras 106

Uma nova língua $\quad 109$

$\begin{array}{ll}\text { Percurso do Leitor, n.4 } & 117\end{array}$

$\begin{array}{lr}\text { Ponto de Partida } & 118\end{array}$

Referências bibliográficas 122 